\title{
V. M. Alexeyev
}

\section{BIBLIOGRAPHY}

These publications are in Russian unless otherwise stated.

1956

[1] Exchange and capture in the three-body problem. Dokl. Akad, Nauk SSSR 108 No. 5 (1956) 599-602.

1958

[2] Existence of a bounded function of the maximal spectral type. Vestnik Mos kouskogo Universiteta, Ser. Matem. Mekh. Astron. Fiz, Khim. No. 5, (1958) 13-15. English translation: Ergod. Th. \& Dynam. Sys. 2 (1982) 259. 1959

[3] Some qualitative results in the three and many-body problems. Candidate Dissertation. Moscow State University, Moscow, 1959.

1960

[4] On the asymptotic behaviour of solutions of slightly non-linear systems of ordinary differential equations. Dokl. Akad. Nauk SSSR 134 No. 2 (1960) 247-250. English translation: Sov. Math. Dokl. 1 1035-1038.

\section{1}

[5] Remarks on criteria of hyperbolic and hyperbolic-elliptic motions. Vestnik Moskouskogo Universiteta, Ser. Fiz, Astron. No. 1 (1961) 67-75.

[6] On an estimate of perturbed solutions of ordinary differential equations, I. Vestnik Moskouskogo Universiteta, Ser. Matem. Mekh. No. 2 (1961) 28-36.

[7] On an estimate of perturbed solutions of ordinary differential equations, II. Vestnik Moskouskogo Universiteta, Ser. Matem. Mekh. No. 3 (1961) 3-10.

[8] A theorem in the theory of perturbed motion. Astron. Zhurnal 38 No. 2 (1961) 325-335. English translation: Soviet Astronomy AJ 5 No. 2, 242-248.

[9] On the theory of perturbed notion. Astron. Zhurnal 38 No. 4 (1961) 726-737. English translation: Soviet Astronomy AJ 5 No. 4, 550-559.

[10] An estimate of the perturbation of hyperbolic motion in the three-body problem. Astron. Zhurnal 38 No. 6 (1961) 1099-1113. English translation: Soviet Astronomy AJ 5 No. 6, 841-849.

1962

[11] On a problem with small parameter. Vestnik Moskouskogo Universiteta, Ser. Matem. Mekh. No. 4 (1962) 17-27.

[12] New examples of capture in the three-body problem. Astron. Zhurnal 39 No. 4 (1962) 724-735. English translation: Soviet Astronomy AJ 6 No. 4, 565-572. 
[13] An example of 'exchange' in the three-body problem with a negative energy constant. Astron. Zhurnal 39 No. 6 (1962) 1102-1111. English translation: Soviet Astronomy AJ 6 No. 6, 858-864.

1963

[14] Final motions in the three-body problem. In Problems of the Motion of Artificial Celestial Bodies. Moscow, Academy of Sciences of the USSR, pp. 50-64.

1965

[15] Generalized three-dimensional problem with two motionless centres. Bull. Inst. Teor. Astr. Akad. Nauk SSSR 10 No. 4 (117), (1965) 241-271.

[16] A theorem on an integral inequality and some of its applications. Mat. Sbornik 68 No. 2 (1965) 251-273. English translation: AMS Trans., Ser. 289 61-88.

1966

[17] Temporary captures in the three-body problem. In Abstracts of Short Com munications of ICM Congress in Moscow, 1966, Section 6, Ordinary Differential Equations, p. 18.

[18] (With R. E. Vinograd). On freezing method. Vestnik Moskouskogo Universiteta Ser. Matem. Mekh No. 5 (1966) 30-35.

[19] International language of science: some mathematical problems at the International Congress in Moscow. Zakarpatskaya Pravda, 3 December 1966.

1967

[20] Quasi-random oscillations of a one-dimensional oscillator. Dokl. Akad. Nauk SSSR 177 No. 3 (1967) 495-498. English translation: Soviet Math. Dokl. 8 No. 6, 1421-1424.

[21] Quasi-random oscillations and the problem of capture in the bounded threebody problem. Dokl. Akad. Nauk SSSR 177 No. 4 (1967) 751-754. English translation: Soviet Math. Dokl. 8 No. 6, 1470-1473

[22] On teaching of the elements of mathematical analysis in ninth grade of special board school N18 associated with Moscow State University. In Mathematical Analysis and Algebra. Moscow: Prosveschenije, 1967, pp. 48-175.

[23] Mathematics-remote and familiar. Komsomoletz, Petrozavodsk, 31 January 1967 and Volzhskii Komsomoletz Kuibyshev, 25 March 1967.

1968

[24] Invariant Markov subsets for diffeomorphisms. Uspehi Mat. Nauk 23 No. 2 (1968) 209-210.

[25] Quasi-random dynamical systems I: Quasi-random diffeomorphisms. Mat. Sbornik 76 No. 1 (1968) 72-134; English translation: Math. of the USSRSbornik 5 No. 1, 73-128.

[26] Quasi-random dynamical systems II: One-dimensional non-linear oscillations in a field with periodic perturbations. Mat. Sbornik 77 No. 4 (1968) 543-601. English translation: Math. of the USSR-Sbornik 6 No. 4, 505560 . 
[27] Quasi-random dynamical systems. Doctoral Dissertation, Moscow State University, Moscow, 1968.

1969

[28] Quasi-random dynamical systems III: Quasi-random oscillations of onedimensional oscillators. Mat. Sbornik 78 No. 1 (1969) 3-50. English translation: Math. of the USSR-Sbornik, 7 No. 1, 1-46.

[29] On possibility of complete capture in the three-body problem for a negative value of full energy. Uspehi Mat. Nauk, 29 No. 1 (1969) 185-186.

[30] Perron sets and topological Markov chains. Uspehi Mat. Nauk 24 No. 5 (1969) 227-228.

[31] Quasi-random dynamical systems; summary of the doctoral dissertation. Matem. Zametki 6 No. 4 (1969) 489-498. English translation: Math. Notes of USSR Acad. Sci. 6 No. 4, 749-753.

1970

[32] Quasi-random oscillations. Proc. 5th Int. Conf. on Non-linear Oscillations, 1969, vol. 2. Kiev: Math. Inst. Ukranian Acad. Sci., 1970, pp. 33-38.

[33] (With S. V. Fomin). Mikhail Valerievich Bebutov, a biography, Uspehi Mat. Nauk 25 No. 3 (1970) 237-239.

1971

[34] Sur l'allure finale du mouvement dans le problème des trois corps. Actes $d u$ Congrès Internationale des Matématiciens, Nice, 1970, tome 2. Paris: GauthierVillars, 1971, pp. 893-907. (In French.)

1972

[35] Quasi-random oscillations and qualitative questions in celestial mechanics. In Ninth Summer Mathematical School. Kiev: Math. Inst. of Ukranian Acad. Sci., 1972, pp. 212-341. English translation: AMS Trans. Ser. 2116. 1973

[36] (With A. V. Kochergin and V. M. El'yasberg). On one method of approximation of processes in uniform biological structures. Automatika i Telemekhanika No. 8 (1973) 52-61. English translation: Automation and Remote Control 34 No. 8, part 1, 1244-1253.

[37] Quasi-random oscillations of one-dimensional oscillators. In Selected papers from All-Union Inter-Iniversity Symp. on Applied Mathematics and Cybernetics, Gorkii, 1967. Moscow, Nauka, 1973, pp. 7-11.

1974

[38] Some multi-dimensional effects in the qualitative theory of differential equations, Talk Summary. Uspehi Mat. Nauk, 29 No. 1 (1974) 159. 1976

[39] Symbolic Dynamics. Eleventh Summer Mathematical School, Kiev 1976, $210 \mathrm{pp}$.

[40] (With A. V. Vasilyev). On the question of mathematical descriptions of impulse flows in neuron networks. In Functional Structure of Analysers (editors: S. V. Fomin, V. I. Guselnikov). Moscow: Isd. MGU, 1976, pp. 86-105. 
[41] (With A. V. Vasilyev). Correlation measures of random impulse flows. The same volume as [40], pp. 106-139.

[42] (With Y. I. Kifer and A. V. Kochergin). On a transformation of random impulse flows by the threshold neuron. The same volume as [40], pp. 140-161. 1977

[43] On one class of dynamical systems. Mathematical Problems in Production Management, No. 7, pp. 30-35.

1979

[44] (With M. V. Jacobson). Symbolic dynamics and hyperbolic dynamical systems. Appendix to the Russian edition of a collection of $\mathbf{R}$. Bowen's works. $\mathbf{R}$. Bowen. Methods of Symbolic Dynamics Moscow, Mir., 1979, pp. 196-241.

[45] (With V. M. Tikhomirov and S. V. Fomin). Optimal Control. Moscow Nauka, 1979,429 pp.

1981

[46] (With nine co-authors) Multi-purpose chart for a heart attack patient. Preprint of Cybernetics Council, USSR Acad. Sci.

[47] Final motions in the three-body problem and symbolic dynamics. Uspehi Math. Nauk 36 No. 4 (1981) 161-182. English translation: Russ. Math. Surveys 36 No. 4.

1982

[48] (With Yu. S. Osipov). Accuracy of Kepler approximation for fly-by orbits near an attracting centre. Ergod. Th. \& Dynam. Sys. 2 (1982) 263. (In English.) 